\title{
Supporting Families in the Neonatal Setting: It's Time to Get Creative!
}

James Nunez K, Griffiths N, Gittany H

Grace Centre for Newborn Intensive Care

Australasian NIDCAP Training Centre

The Children's Hospital at Westmead, Sydney, Australia

\section{Background}

In New South Wales, The Children's Hospital at Westmead $(\mathrm{CHW})$ is part of a regionalised health system where infants who require intensive care for surgery in the newborn period are often transported to the CHW via a Newborn Transport Service or the woman is transferred for delivery at a High Risk Obstetric Unit associated with a Children's Hospital. This often means families are separated and there are competing needs of families, siblings and work commitments many kilometres from the Grace Centre for Newborn Intensive Care (GCNIC). In 2017, staff in the GCNIC started a Family Support Volunteer (FSV) Program designed to help support parents when they need to leave the hospital for periods of time for other obligations which may include work, family commitments and/or geographical distance from the hospital. The priority remains the attachment of the infant to their parents and supporting the family through an individualised approach to care, frequent open communication and promoting opportunities for the parents to be involved in their infants' care.

\section{Aim}

To describe the implementation of a unit-based Family Support Volunteer (FSV) Program to support parents and their babies who are in the NICU for surgery.

\section{Methods}

Following recommendations from a NIDCAP Advanced Practicum in 2017, a program to support families in instances where it is not possible for them to always be present with their babies was implemented. Twelve FSV's were recruited from the hospital's existing ward volunteer program. Volunteers with prior experience working in hospital clinical areas and with an expressed interest in working in the NICU were each offered six to 12 hours per week in the FSV role. They were provided with a fourhour orientation program facilitated by a NIDCAP Trainer and a social worker. Training included basic skills for: the identification of infant stress signals; support and comfort through positioning; ways to hold and talk to the baby whilst offering support; and acknowledgement of the role of the parents within the NICU. Families and babies were recruited to the program by the FSV using an opt in/opt out parent consent process; bedside documentation identified families who consented for inclusion. The project was endorsed by the Executive Director of Nursing and had ethical approval through the clinical governance unit of the organisation. Following a ten month trial, a survey was distributed to the volunteers, families and staff to gauge the success of the program and to identify if changes were required. The survey was distributed electronically by the program coordinator and consisted of ten open-ended and yes/no questions. The online survey was open for completion for four weeks.

\section{Results}

Ten families were surveyed regarding the FSV program. Eight $(80 \%)$ of respondents had used the program. All $(100 \%)$ of families that used the program identified they would recommend the program to other families.

One hundred percent of the FSV's completed the evaluation. They indicated the majority of their time was spent comforting babies, followed by recruiting families to the program.

Ninety-two percent of staff $(\mathrm{n}=28)$ indicated a Family Support Volunteer had assisted them by providing comfort to newborn infants under their care. All (100\%) of the respondents found the support offered by FSV's useful by reducing periods of crying and distress for babies. Eighty-nine percent of staff identified the presence of FSV's allowed them to complete other tasks.

\section{Conclusion}

The Family Support Volunteers provided an important role in the NICU by helping parents when they were unable to be present with their baby. The collaboration between the volunteers, families and staff has resulted in the needs of the babies being met to reduce crying periods and settling the babies following interventions.

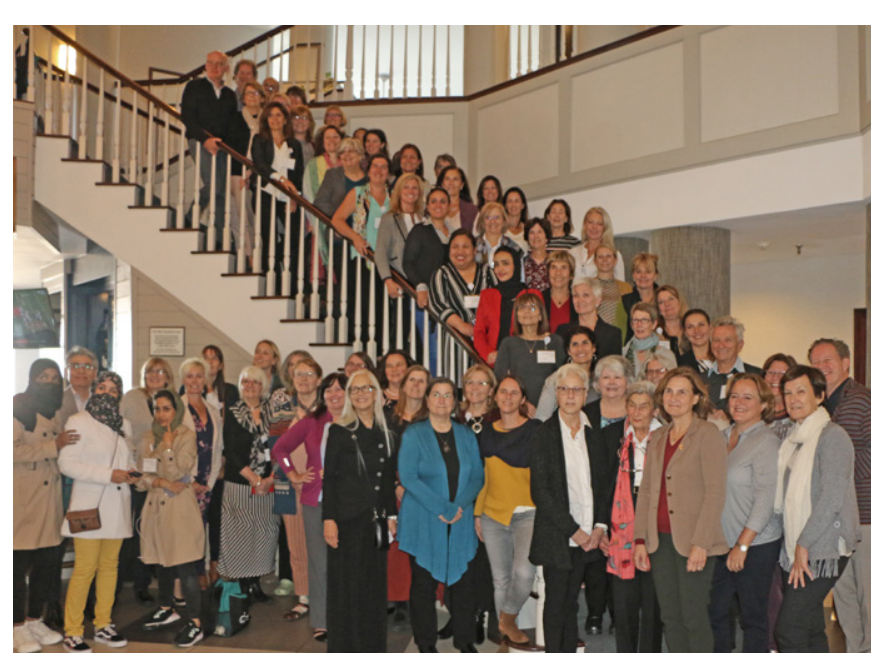

The $30^{\text {th }}$ Annual NIDCAP Trainers Meeting 